\title{
Studi Analisis Kapasitas Pengaman Kopel dalam Mensuplai Daya di Bandara Internasional Ngurah Rai Saat Hilangnya Suplai Daya Dari Penyulang Gayatri atau Penyulang Bandara
}

\author{
I.G.A.Yoga Armika ${ }^{1}$, I.G. Dyana Arjana ${ }^{2}$, I.W. Rinas ${ }^{3}$
}

\begin{abstract}
Abstrak- Loss of electrical power supply can be caused by a disruption or work network, to maintain the continuity of power at Ngurah Rai International Airport when a loss of power supply maneuver the load. Maneuver the load carried by the connecting bus service burden I and II using the service load bus coupling aid. Kopel include safety relays overcurrent works by comparing a large input current by setting relay. The results obtained after the analysis by manual calculation is the nominal value of the burden of service I and load Airports II of 300 A, obtained the current setting is the coupling of Iset $=180 \mathrm{~A}$, the working time rele 0.025 seconds with Tms $=0.052$ SI and for setting GFR obtained setting a current of ISET $=28028 \mathrm{~A}$ with Tms $=0.008$ SI. Simulations done by giving disturbance on the bus load of service I, where the relay will work with a time of 0.025 seconds to instruct PMT on the coupling loose, so it does not interfere with the network on the side feeder Ngurah Rai I and feeder Ngurah Rai II, so that the continuity of load power Airports II to stay awake.

Keywords: Over Current Protection Relay (OCR), ETAP program Powerstation.
\end{abstract}

\begin{abstract}
Abstrak- Hilangnya suplai daya listrik dapat diakibatkan oleh gangguan atau pekerjaan jaringan, untuk menjaga kontinuitas daya listrik di bandara Internasional Ngurah Rai saat hilangnya suplai daya dilakukan manuver beban. Manuver beban dilakukan dengan menghubungkan bus beban Bandara I dan bus beban Bandara II menggunakan bantuan kopel . Kopel dilengkapi pengaman rele arus lebih yang bekerja dengan membandingkan besar input arus dengan setting rele. Hasil yang diperoleh setelah analisa dengan perhitungan manual yaitu nilai nominal beban Bandara I dan beban Bandara II sebesar 300 A, didapat setting arus lebih pada kopel sebesar $I_{\text {set }}=180$ A, waktu kerja rele 0.025 detik dengan $\mathrm{Tms}=0.052$ SI dan untuk setting GFR didapat setting arus sebesar $I_{\text {set }}=28.028$ A dengan Tms $=0,008$ SI. Simulasi dilakukan dengan memberi gangguan di bus beban Bandara I, dimana rele akan bekerja dengan waktu 0.025 detik untuk memerintahkan PMT pada kopel lepas, sehingga tidak mengganggu jaringan di sisi Penyulang Ngurah Rai I dan Penyulang Ngurah Rai II, sehingga kontinuitas daya beban Bandara II tetap terjaga.
\end{abstract}

Kata Kunci : Proteksi Over Current Relay (OCR), Program ETAP Powerstation.

${ }^{\mathrm{I}}$ Mahasiswa, Jurusan Teknik Elektro dan Komputer Fakultas Teknik Universitas Udayana, Jln. Kampus Bukit Jimbaran 80361 INDONESIA (telp: 0361-703315; fax: 0361-4321;

e-mail:yogaarmika@gmail.com

${ }^{2,3}$ Dosen, Jurusan Teknik Elektro dan Komputer Fakultas Teknik Universitas Udayana, Jln. Kampus Bukit Jimbaran 80361 INDONESIA (telp: 0361-703315; fax: 0361-4321;

e-mail: ${ }^{1}$ dyanaarjana@unud.ac.id, ${ }^{2}$ rinas@unud.ac.id,

\section{Pendahuluan}

Beban Bandara Internasional Ngurang Rai terbagi menjadi 2, yakni beban Bandara I dan beban Bandara II. Apabila terjadi hilangnya daya listrik pada Penyulang Gayatri, dan Penyulang Bandara tidak berfungsi untuk menggantikan mensuplai daya maka beban Bandara I akan padam sehingga dapat mengakibatkan dampak buruk pada sistem operasi penerbangan. Pengalihan suplai daya listrik dari penyulang Ngurah Rai I dan penyulang Ngurang Rai II dapat dilakukan dengan menghubungkan kopel yang menghubungkan bus beban Bandara I dan beban Bandara II.

Penelitian yang telah dilakukan sebelumnya dengan judul "Analisa Koordinat Setting Rele Pengaman Akibat Uprating di Gardu Induk Gianyar" membahas tentang setting rele di setiap zona pengaman. Pada kopel yang menghubungkan bus beban penyulang I dan penyulang II di zona IV, dilakukan setting rele kembali akibat uprating transformator sehingga didapat setting rele yang akurat di setiap zona [1]. Untuk menghindari terjadi arus lebih yang dapat mengakibatkan padam total (blackout) saat melakukan pengalihan suplai daya maka salah satu cara untuk menghilangkan gangguan tersebut adalah memutus aliran daya yang berasal dari Penyulang Ngurah Rai I dan II[2].

Arus beban puncak Bandara I dari penyulang Gayatri sebesar 143A. sedangkan pada Bandara II arus beban puncak dari penyulang Ngurah Rai I dan II sebesar 166 A [3]. Berdasarkan kondisi yang telah dijabarkan di atas, memungkinkan dilakukan pengalihan suplai daya dari Penyulang Ngurah Rai I dan Penyulang Ngurah Rai II. Sebelum melakukan pengalihan suplai daya perlu diketahui kemampuan kapasitas pengaman kopel yang menghubungkan bus beban Bandara I dan beban Bandara II.

\section{Sistem Distribusi Dan PEngaman Tenaga Listrik}

A. Sistem Distribusi Tenaga Listrik

Saluran distribusi merupakan suplai tenaga listrik ke beban atau konsumen melalui tahapan-tahapan seperti pembangkitan, transmisi, dan saluran distribusi itu sendiri. Saluran distribusi yang umum digunakan antara lain[4]:

1. Sistem jaringan distribusi primer

Sistem distribusi primer digunakan untuk menyalurkan tenaga listrik ke pusat beban, sistem ini dapat menggunakan kabel udara ataupun kabel tanam sesuai tingkat keandalan dan kondisi lingkungan 
2. Sistem jaringan distribusi sekunder.

Sistem jaringan distribusi sekunder digunakan untuk menyalurkan tenaga listrik dari gardu distribusi sampai ke sambungan rumah dengan tegangan rendah 220 Volt. Adapun alur pendistribusian listrik sebagai berikut:

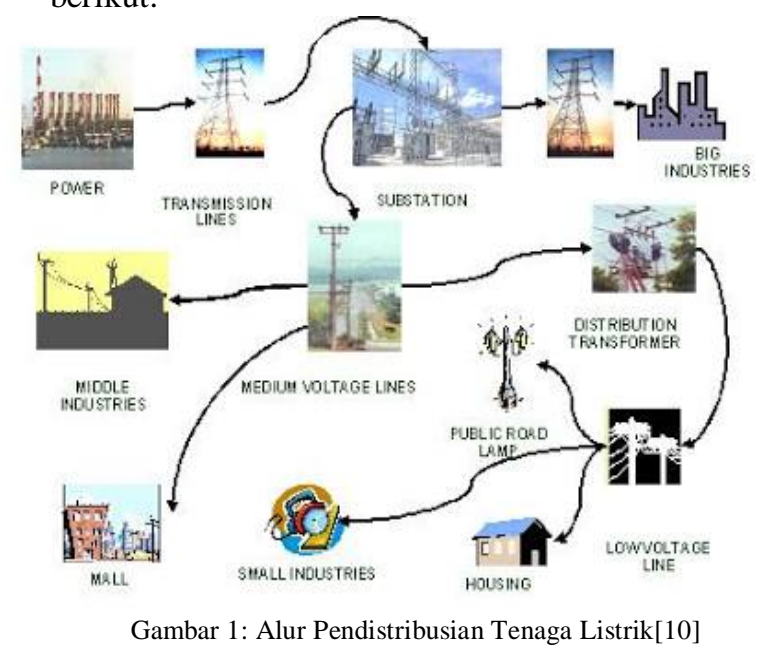

\section{B. Sistem Pengaman Tenaga Listrik}

Pada umumnya sistem pengaman tenaga listrik dirancang untuk mengidentifikasi informasi yang diproleh dari sistem tersebut seperti arus, tegangan, atau sudut fasa antara keduanya. Informasi yang didapat akan digunakan untuk melakukan perbandingan besarannya dengan besaran ambang batas (threshold setting) pada peralatan proteksi[5]. Apabila melebihi ambang batas maka sistem proteksi akan bekerja untuk mengamankan kondisi tersebut. Kondisi abnormal yang terjadi akibat gangguan antara lain:

1. Hubung singkat

2. Tegangan lebih/kurang

3. Beban lebih

4. Frekuensi sistem turun/naik

Apabila proteksi distribusi tenaga listrik baik, maka nilai ekonomis dapat diproleh karena jika dalam suatu distribusi dan transmisi terjadi gangguan, maka kerusakan peralatan tidak menyebar ke peralatan yang lain.

\section{Rele Arus Lebih (Over Current Relay)}

Rele arus lebih merupakan rele yang bekerja berdasarkan adanya kenaikan arus yang melebihi nilai tertentu yang melewatinya, rele ini akan bekerja pada jangka waktu yang telah ditentukan[5]. Rele arus lebih dapat dibagi sebagai berikut[6] :

1. Rele arus lebih seketika (Instantaneous)

Rele ini bekerja dengan sanggat singkat berkisar 20100 mili second tanpa waktu tunda.

2. Rele Arus Lebih Waktu tertentu (Definite Time)

Rele ini bekerja dengan jangka waktu tertentu dan tidak hanya tergantung dari besarnya arus yang menggerakan.

3. Rele arus lebih waktu terbalik (Inverse Time)
Rele ini mempunyai sifat waktu terbalik untuk nilai arus yang kecil dan mempunyai sifat waktu tertentu untuk nila arus yang lebih besar.

\section{Perhitungan Impedansi Eqivalen}

Impedansi eqivalen untuk menghitung arus hubung singkat terdiri dari impedansi eqivalen urutan positif $\left(Z_{1 \text { leq }}\right)$, impedansi eqivalen urutan negatif $\left(Z_{1 \text { eq }}\right)$ dan impedansi eqivalen urutan nol $\left(Z_{0 \text { eq }}\right)$, untuk nilai $Z_{1 \text { eq }}=Z_{2 \text { eq }}$ sehingga perhitungan[5] :

$$
\begin{gathered}
Z_{\text {leq }}=Z_{\mathrm{s} 2}+Z_{t 1}+Z_{\text {lpenyulang }} \\
\text { dan } Z_{0 \text { eq }}=Z_{t 0}+3 R_{n}+Z_{\text {openyulang }}
\end{gathered}
$$

Keterangan

$\mathrm{Z}_{\text {leq }}=$ Impedansi eqivalen urutan positif

$\mathrm{Z}_{2 \mathrm{eq}}=$ Impedansi eqivalen urutan negatif

$\mathrm{Z}_{0 \mathrm{eq}}=$ Impedansi eqivalen urutan nol

$\mathrm{Z}_{\mathrm{s} 2}=$ Impedansi sumber

$\mathrm{Z}_{\mathrm{t} 1}=$ Impedansi transformator tenaga

$\mathrm{Z}_{\mathrm{t} 0}=$ Impedansi transformator tenaga urutan nol

$3 \mathrm{R}_{\mathrm{n}}=\mathrm{NGR}$ (nilai tahanan pembumian)

$\mathrm{Z}_{1 \text { penyulang }}=$ Impedansi jaringan distribusi

$\mathrm{Z}_{\text {Openyulang }}=$ Impedansi urutan nol penyulang

\section{E. Prinsip Dasar Perhitungan Arus Hubung Singkat}

Gangguan hubung singkat dapat menimbulkan arus yang jauh lebih besar dari pada arus normal, dan dapat menimbulkan kerusakan peralatan jaringan serta mengganggu batas-batas kestabilan sistem daya[7]. Gangguan hubung singkat yang sering terjadi dalam pendistribusian tenaga listrik yaitu[5] :

1. Gangguan Hubung Singkat 1 fasa

$$
\mathrm{I}_{\mathrm{hs} 1 \varnothing(20 \mathrm{kV})}=\frac{3 \cdot \frac{\left(\mathrm{V}_{\mathrm{S}} \cdot 10^{3}\right)}{\sqrt{3}}}{\left(2 \cdot \mathrm{Z}_{1 \mathrm{eq}}\right)+\mathrm{Z}_{0 \mathrm{eq}}}
$$

2. Gangguan Hubung singkat 2 fasa

$$
\mathrm{I}_{\mathrm{hs} 2 \varnothing(20 \mathrm{kV})}=\frac{\mathrm{V}_{\mathrm{s}} \cdot 10^{3}}{2 \cdot \mathrm{Z}_{\mathrm{Ieq}}}
$$

3. Gangguan Hubung Singkat 3 fasa

$$
\mathrm{I}_{\mathrm{hs} 3 \varnothing(20 \mathrm{kV})}=\frac{\mathrm{V}_{\mathrm{s}} \cdot 10^{3} / \sqrt{3}}{\mathrm{Z}_{1 \mathrm{eq}}}
$$

Keterangan :

$$
\begin{aligned}
& \mathrm{I}_{\mathrm{hs} 1 \varnothing}=\text { Arus hubung singkat } 1 \text { fasa } \\
& \mathrm{I}_{\mathrm{hs} 2 \varnothing}=\text { Arus hubung singkat } 2 \text { fasa } \\
& \mathrm{I}_{\mathrm{hs} 3 \varnothing}=\text { Arus hubung singkat } 3 \text { fasa } \\
& \mathrm{V}_{\mathrm{s}}=\text { Tegangan sisi sekunder } \\
& \mathrm{Z}_{\text {leq }}=\text { Impedansi eqivalen urutan positif } \\
& \mathrm{Z}_{0 \mathrm{eq}}=\text { Impedansi eqivalen ururtan nol }
\end{aligned}
$$

\section{F. Perhitungan Setting Arus dan Waktu Rele Arus Lebih}

Rele arus lebih tidak boleh bekerja pada keadaan beban maksimum, sehingga nominal tranformator arus (CT) merupakan arus maksimumnya[5]. Berikut merupakan perhitungan setting arus :

$$
\begin{aligned}
& \mathrm{I}_{\mathrm{set}}=\frac{1,2 \cdot \mathrm{I}_{\mathrm{p}}}{\mathrm{CT} \mathrm{p}} \\
& \text { Keterangan : } \\
& \mathrm{I}_{\text {set }}=\text { Setelan arus } \\
& \mathrm{I}_{\mathrm{p}} \quad=\text { Arus nominal pada sisi primer }
\end{aligned}
$$


$\mathrm{CT}_{\mathrm{p}}=$ Rasio transformator arus pada sisi primer

Untuk setting waktu pada rele dibuat secara bertingkat agar medapatkan pengaman yang selektif. Pada jaringan distribusi Time Multiple Setting (TMS) dan setelan waktu menggunakan Standard Inverse yang dihitung menggunakan rumus kurva waktu terhadap arus. Berikut merupakan perhitungan nilai TMS dan waktu aktual[5]:

$$
\begin{aligned}
\operatorname{Tms} & =\frac{\mathrm{t} \cdot \frac{\left(\mathrm{I}_{\text {fault }}\right) \mathrm{a}}{\mathrm{I}_{\text {set }}}-1}{\beta} \\
\mathrm{dan} & \\
\mathrm{t} & =\frac{\beta \cdot \mathrm{tms}}{\frac{\left.\mathrm{I}_{\text {fault }}\right) \mathrm{a}}{\mathrm{I}_{\text {set }}}-1}
\end{aligned}
$$

Keterangan :

$$
\begin{array}{ll}
\text { Tms } & =\text { Time Multiple Setting } \\
\mathrm{t} & =\text { waktu kerja } \\
\mathrm{I}_{\text {fault }} & =\text { Arus gangguan hubung singkat } \\
\mathrm{I}_{\text {set } \mathrm{p}} & =\text { Arus setting sisi primer } \\
\alpha, \beta & =\text { Konstanta }
\end{array}
$$

TABEL 1

KONSTANTA $\alpha$ DAN $\beta[6]$

\begin{tabular}{|c|c|c|}
\hline Nama Kurva & $\boldsymbol{\alpha}$ & $\boldsymbol{\beta}$ \\
\hline Standard Inverse & 0.02 & 0.14 \\
\hline Very Inverse & 1 & 13.2 \\
\hline Extremely Inverse & 2 & 80 \\
\hline
\end{tabular}

\section{Metode Penelitian}

\section{A. Tempat dan Waktu Penelitian}

Penelitian dan analisis dilakukan di PT.PLN (Persero) Distribusi Bali Area Bali Selatan, dengan waktu pelaksanaan penelitian dimulai pada bulan Pebruari 2016.

\section{B. Sumber dan Jenis Data}

Sumber data dalam pembahasan penelitian ini berupa data sekunder yang diperoleh dari PT.PLN (Persero) Distribusi Bali Area Bali Selatan dan studi literatur serta sumber-sumber lainnya. Jenis data yang digunakan dalam penyusunan penelitian ini adalah data kuantitatif, yaitu berupa angka- angka yang terkait dengan data historis beban pada Penyulang Gayatri dan Penyulang Bandara yang terdapat dalam sistem distribusi Bandara Internasional Ngurah Rai Bali. C. Analisis Data

Analisis dalam penelitian ini dilakukan dalam beberapa tahapan sebagai berikut :

1. Pengumpulan dan analisis data beban dan spesifikasi penghantar penyulang Gayatri dan penyulang Bandara.

2. Melakukan perhitungan manual penggunaan daya listrik beban Bandara I dan beban Bandara II.

3. Menganalisa kapasitas pengaman kopel dengan melakukan setting rele.

\section{Diagram Alur analisis}

Alur analisis yang digunakan dalam penulisan penelitian ini dapat dilihat pada Gambar 2.

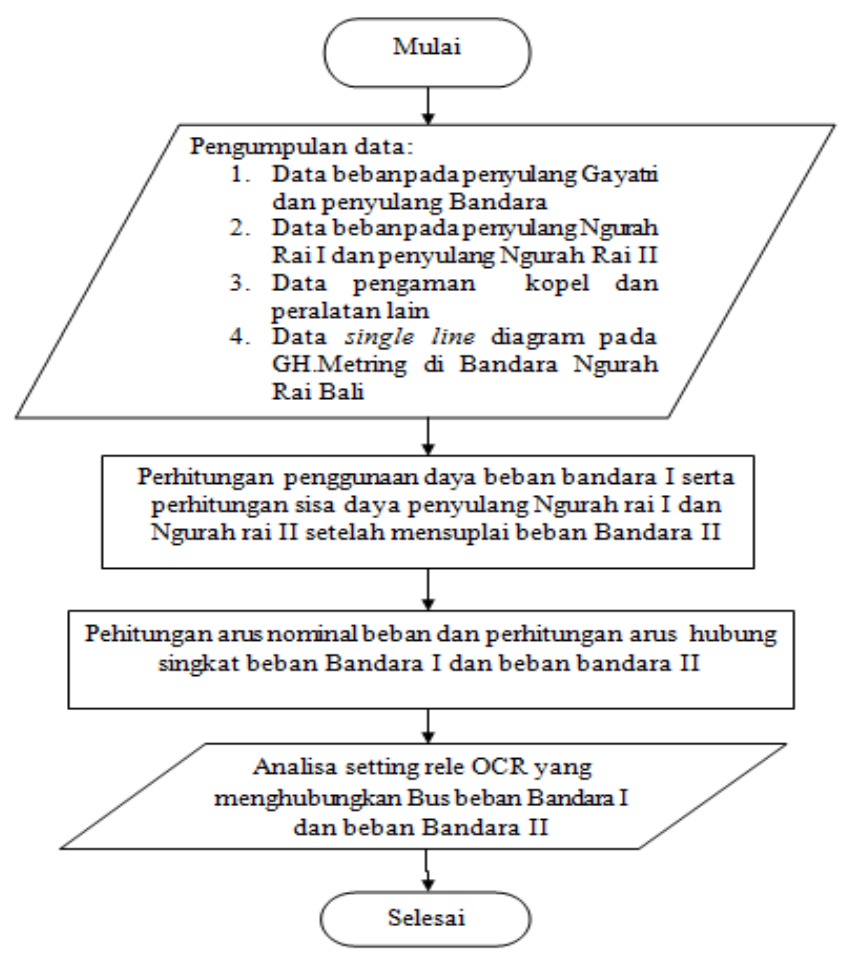

Gambar 2: Alur Analisis Penelitian

\section{PEMBAHASAN DAN ANALISIS}

Bandara Internasional Ngurah Rai merupakan pelanggan ber-daya besar yang membutuhkan suplai daya khusus. Berikut ini gambar single line diagram dan data pengantar di penyulang yang akan digunakan untuk melakukan perhitungan dan simulasi di Bandara Internasional Ngurah Rai[8].

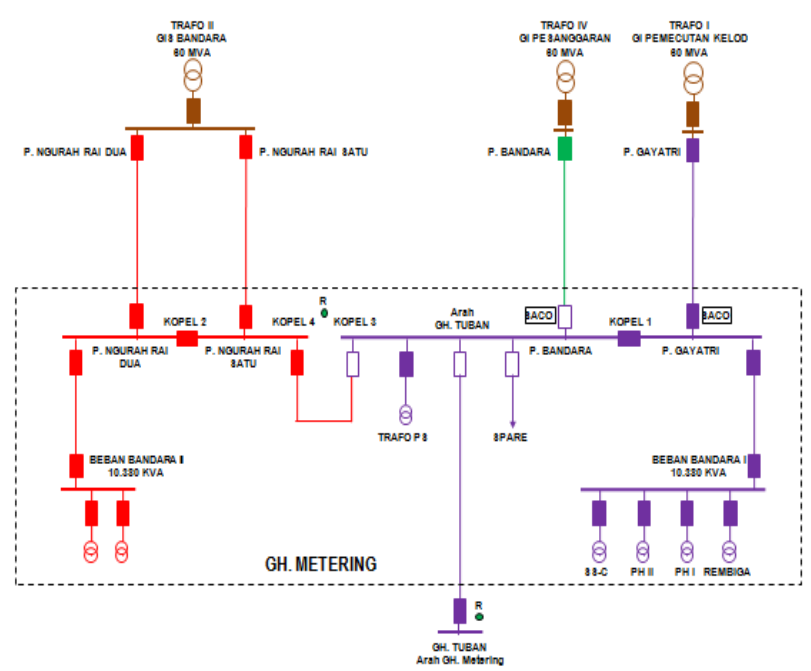

I Gede Agus Yoga Armika : Studi Analisis Kapasitas Pengaman.... 
Gambar 3: single line diagram GH.Metering[8]

TABEL 2

DATA PENGANTAR PENYUlang Di BANDARA INTERNASIONAL NGURAH RAI[9]

\begin{tabular}{|c|c|c|c|c|c|c|}
\hline Penyulang & $\begin{array}{c}\text { Jenis } \\
\text { Pengantar }\end{array}$ & $\begin{array}{c}\text { Panjang } \\
\text { Pengantar }\end{array}$ & $\begin{array}{c}\mathrm{Z}_{1} \mathrm{R} \\
\Omega \\
/ \mathrm{km}\end{array}$ & $\begin{array}{r}\mathrm{Z}_{1} \mathrm{X} \\
\Omega \\
/ \mathrm{km}\end{array}$ & $\begin{array}{r}\mathrm{Z}_{0} \mathrm{R} \\
\Omega \\
/ \mathrm{km}\end{array}$ & $\begin{array}{r}\mathrm{Z}_{0} \mathrm{X} \\
\Omega \\
/ \mathrm{km}\end{array}$ \\
\hline $\begin{array}{c}\text { P. Ngurah } \\
\text { Rai } \\
\text { I dan II }\end{array}$ & $\begin{array}{c}\text { NA2XSE } \\
\text { YBY } \\
\begin{array}{c}3 \times 300 \\
\mathrm{~mm}^{2}\end{array}\end{array}$ & $4.531 \mathrm{Km}$ & 0.130 & 0.289 & 0.250 & 0.282 \\
\hline P. Gayatri & $\begin{array}{c}\mathrm{MVTIC} \\
150 \mathrm{~mm}^{2}\end{array}$ & $7.2 \mathrm{Km}$ & 0.265 & 0.106 & 0.363 & 1.618 \\
\hline
\end{tabular}

\section{A. Perhitungan Arus Hubung Singkat}

Untuk menghitung arus hubung singkat di penyulang terlebih dahulu menghitung nilai impedansi eqivalen penyulang dengan menggunakan persamaan (1) dan (2), sehingga didapat hasil perhitungan untuk nilai impedansi eqivalen penyulang Ngurah Rai I dan II pada table 3:

TABEL 3

HASIL PERHITUNGAN NILAI IMPEDANSI EQIVALEN PENYULANG NGURAH RAI I DAN II

\begin{tabular}{|c|c|c|}
\hline \multirow[b]{2}{*}{$\begin{array}{c}\% \\
\text { Penyulang }\end{array}$} & \multicolumn{2}{|c|}{ Penyulang Ngurah Rai I dan II } \\
\hline & $\begin{array}{c}\text { Impedansi positif dan negative } \\
\qquad \mathrm{Z}_{\mathrm{leq}}=\mathrm{Z}_{2 \mathrm{eq}}\end{array}$ & $\begin{array}{l}\text { Impedansi nol } \\
\mathrm{Z}_{\text {0eq }}\end{array}$ \\
\hline $1 \%$ & $0.005+\mathrm{j} 0.981$ & $120.011+\mathrm{j} 2.511$ \\
\hline $100 \%$ & $0.589+\mathrm{j} 2.278$ & $121.133+\mathrm{j} 3.777$ \\
\hline
\end{tabular}

Perhitungan nilai eqivalen penyulang Gayatri juga menggunakan persamaan (1) dan (2), sehingga didapat hasil perhitungan pada tabel 4:

TABEL 4

HASIL PERHITUNGAN NILAI IMPEDANSI EQIVALEN PENYULANG GAYATRI

\begin{tabular}{|c|c|c|}
\hline \multirow{3}{*}{$\%$ Penyulang } & \multicolumn{2}{|c|}{ Penyulang Gayatri } \\
\cline { 2 - 3 } & Impedansi positif dan negative & $\begin{array}{c}\text { Impedansi nol } \\
\mathrm{Z}_{\text {1eq }}=\mathrm{Z}_{2 \mathrm{eq}}\end{array}$ \\
\hline $1 \%$ & $0.019+\mathrm{j} 0.940$ & $120.026+\mathrm{j} \mathrm{j} 8.446$ \\
\hline $100 \%$ & $1.908+\mathrm{j} 1.695$ & $122.613+19.979$ \\
\hline
\end{tabular}

Perhitungan arus hubung singkat penyulang ngurah rai I dan II dengan menggunakan persamaan (3), (4), dan (5) di dapatkan hasil perhitungan pada tabel 5:

TABEL 5

Hasil PERHITUNGAN ARUS HubUNG SingKat PENYUlANG NGURAH RAI I DAN II

\begin{tabular}{|c|c|c|c|}
\hline \multirow{2}{*}{$\begin{array}{c}\% \\
\text { Penyulang }\end{array}$} & \multicolumn{3}{|c|}{ Penyulang Ngurah Rai I dan II } \\
\cline { 2 - 4 } & $\mathrm{I}_{\mathrm{hs}} 3 \varnothing 20 \mathrm{kV}$ & $\mathrm{I}_{\mathrm{hs}} 2 \varnothing 20 \mathrm{kV}$ & $\mathrm{I}_{\mathrm{hs}} 1 \varnothing 20 \mathrm{kV}$ \\
\hline $1 \%$ & 11770.49 & 10193.55 & 288.424 \\
\hline $100 \%$ & 4907.534 & 4250.049 & 280.284 \\
\hline
\end{tabular}

Perhitungan arus hubung singkat penyulang Gayatri menggunakan persamaan (3),(4) dan (5), sehingga didapat hasil perhitungan pada tabel 6 :
TABEL 6

HASIl PERHITUNGAN ARUS HubUNG SingKat PENYULANG GAYATRI

\begin{tabular}{|c|c|c|c|}
\hline \multirow{2}{*}{$\begin{array}{c}\% \\
\text { Penyulang }\end{array}$} & \multicolumn{3}{|c|}{ Penyulang Gayatri } \\
\cline { 2 - 4 } & $\mathrm{I}_{\mathrm{hs}} 3 \varnothing 20 \mathrm{kV}$ & $\mathrm{I}_{\mathrm{hs}} 2 \varnothing 20 \mathrm{kV}$ & $\mathrm{I}_{\mathrm{hs}} 1 \varnothing 20 \mathrm{kV}$ \\
\hline $1 \%$ & 12281.54 & 10.636 .13 & 287.460 \\
\hline $100 \%$ & 4524.416 & 3918.259 & 269.431 \\
\hline
\end{tabular}

\section{B. Setting Rele Penyulang Ngurah Rai I dan II}

Data existing yang di dapat dari PT.PLN (Persero) APD Bali tidak ditemukan setting rele pada kopel 3 yang menghubungkan bus beban Bandara I dan beban Bandara II, dikarenakan belum dilakukannya setting rele pada kopel 3 . TABEL 6

DATA EXISTING SETTING RELE PENYULANG NGURAH RAI I DAN II[10]

\begin{tabular}{|c|c|c|c|c|c|c|c|}
\hline \multirow{2}{*}{ Setting } & \multicolumn{4}{|c|}{ Setting phase - phase } & \multicolumn{3}{c|}{ Setting Phase - tanah } \\
\cline { 2 - 8 } & CT & Iset & Waktu & Curva & Iset & waktu & Curva \\
\hline $\begin{array}{c}\text { P. } \\
\text { Ngurah } \\
\text { Rai I }\end{array}$ & $600 / 1$ & 336 & 0.2 & SI & 50 & 0.200 & SI \\
\hline $\begin{array}{c}\text { P. } \\
\text { Ngurah } \\
\text { Rai II }\end{array}$ & $600 / 1$ & 336 & 0.2 & SI & 50 & 0.200 & SI \\
\hline GH1 & $600 / 5$ & 328 & 0.12 & SI & 36 & 0.12 & SI \\
\hline GH2 & $600 / 5$ & 328 & 0.12 & SI & 36 & 0.12 & SI \\
\hline Kopel 3 & - & - & - & - & - & - & - \\
\hline
\end{tabular}

Sebelum menghitung setting arus rele di Penyulang, maka harus diketahui arus beban $\left(\mathrm{I}_{\mathrm{b}}\right)$ terlebih dahulu. Diketahui daya pelanggan di Penyulang Ngurah Rai I dan II untuk Beban Bandara II sebesar 10.380 kVA, sehingga perhitungan dilakukan untuk mendapat nilai $\mathrm{I}_{\mathrm{b}}$ sebagai berikut :

$$
\begin{aligned}
& \mathrm{I}_{\mathrm{b}}=\frac{\mathrm{S}}{\mathrm{V} \cdot \sqrt{3}} \\
& \mathrm{I}_{\mathrm{b}}=\frac{10380 \mathrm{kVA}}{\mathrm{V} \cdot \sqrt{3}} \\
& \mathrm{I}_{\mathrm{b}}=300 \mathrm{~A}
\end{aligned}
$$

Jadi arus beban untuk perhitungan setting rele adalah 300 A.

Perhitungan setting arus primer dan sekunder rele arus lebih dihitung dengan menggunakan nilai arus beban yaitu 300 A dan untuk perhitungan nilai Tms dengan karakteristik standard inverse menggunakan gangguan hubung singkat penyulang Ngurah Rai I dan II terbesar yaitu 11770.49 A, perhitungan sebagai berikut:

1. Perhitungan Setting Over Current Relay di sisi GI dengan menggunakan persamaan (6)

$$
\begin{aligned}
\mathrm{I}_{\text {set }(\mathrm{p})} & =1.2 \times \mathrm{I}_{\mathrm{b}} \\
& =1.2 \times 300 \\
& =360 \mathrm{~A} \\
\mathrm{I}_{\text {set }(\mathrm{s})} & =\left(1.2 \times \mathrm{I}_{\mathrm{b}}\right) / \mathrm{CT} \\
& =360 /(600 / 1)
\end{aligned}
$$




$$
=0.6 \mathrm{~A}
$$

Perhitungan Time Multiple Setting dan waktu actual dengan menggunakan persamaan (7),(8)

$$
\begin{aligned}
\text { Tms } & =\frac{t \frac{\left(I_{\text {fault }}\right) a}{I_{\text {set }}}-1}{0.14} \\
& =\frac{0.3 \cdot\left[\left(\frac{11770.49}{360}\right)^{0.02}-1\right]}{0.14} \\
& =0.154 \mathrm{SI} \\
\mathrm{t} & =\frac{0.14 \mathrm{tms}}{\frac{\left.\mathrm{I}_{\text {fault }}\right) \mathrm{a}}{\mathrm{I}_{\text {set }}}-1} \\
& =\frac{0.14 .0 .154}{\left(\frac{11770.49}{360}\right)^{0.02}-1} \\
& =0.3 \text { detik }
\end{aligned}
$$

2. Perhitungan Setting Over Current Relay di sisi GH dengan menggunakan persamaan (6)

$$
\begin{aligned}
\mathrm{I}_{\text {set (p) }} & =1.1 \times \mathrm{I}_{\mathrm{b}} \\
& =1.1 \times 300 \\
& =330 \mathrm{~A} \\
\mathrm{I}_{\text {set }(\mathrm{s})} & =\left(1.1 \times \mathrm{I}_{\mathrm{b}}\right) / \mathrm{CT} \\
& =330 /(600 / 5) \\
& =2.75 \mathrm{~A}
\end{aligned}
$$

Perhitungan Time Multiple Setting dan waktu actual dengan menggunakan persamaan (7), (8)

$$
\begin{aligned}
\text { Tms } & =\frac{t \frac{\left(I_{\text {fault }}\right) a}{I_{\text {set }}}-1}{0.14} \\
& =\frac{0.1 \cdot\left[\left(\frac{11770.49}{330}\right)^{0.02}-1\right]}{0.14} \\
& =0.052 \mathrm{SI} \\
\mathrm{t} & =\frac{0.14 . \mathrm{tms}}{\frac{\left(I_{\text {fault }}\right) \mathrm{a}}{\mathrm{I}_{\text {set }}}-1} \\
& =\frac{0.14 .0 .052}{\left(\frac{11770.49}{330}\right)^{0.02}-1} \\
& =0.1 \text { detik }
\end{aligned}
$$

3. Perhitungsn setting Over Current Relay di sisi Kopel dengan menggunakan persamaan (6)

$$
\begin{aligned}
\mathrm{I}_{\text {set (p) }} & =0.6 \times \mathrm{I}_{\text {beban }} \\
& =0.6 \times 300 \\
& =180 \mathrm{~A} \\
\mathrm{I}_{\text {set (s) }} & =\left(0.6 \times \mathrm{I}_{\mathrm{b}}\right) / \mathrm{CT} \\
& =180 /(400 / 5) \\
& =2.25 \mathrm{~A}
\end{aligned}
$$

Perhitungan Time Multiple Setting dan waktu actual dengan menggunakan persamaan (7),(8)

$$
\begin{aligned}
\text { Tms } & =\frac{t \cdot \frac{\left(I_{\text {fault }}\right) a}{I_{\text {kplset }}}-1}{0.14} \\
& =\frac{0.025 \cdot\left(\frac{11770.49}{180}\right)^{0.02}-1}{0.14} \\
& =0.015 \mathrm{SI}
\end{aligned}
$$

$$
\begin{aligned}
\mathrm{t} & =\frac{0.14 \mathrm{tms}}{\frac{\left(I_{\text {fault }}\right) a}{I_{\text {set }}}-1} \\
& =\frac{0.14 .0 .015}{\left(\frac{11770.49}{180}\right)^{0.02}-1} \\
& =0.025 \text { detik }
\end{aligned}
$$

Untuk memperoleh setting Ground Fault Relay digunakan nilai arus hubung singkat 1 fasa terkecil Penyulang Ngurah Rai I dan II sebesar 280.284 A, perhitungan sebagai berikut:

1. Perhitungan Setting Ground Fault Relay di sisi GI

$$
\begin{aligned}
\mathrm{I}_{\text {set (p) }} & =12 \% \times \text { Ifault } 1 \text { fasa ketanah } \\
& =0,12 \times 280.284 \\
& =33.634 \mathrm{~A} \\
\mathrm{I}_{\text {set (s) }} & =\mathrm{I}_{\text {set }(\mathrm{p})} / \mathrm{CT} \\
& =33.634 /(600 / 1) \\
& =0.056 \mathrm{~A}
\end{aligned}
$$

Perhitungan Time Multiple Setting dan waktu actual dengan menggunakan persamaan (7),(8)

$$
\begin{aligned}
\text { Tms } & =\frac{t \cdot \frac{\left(I_{\text {fault }}\right) a}{I_{\text {set }}}-1}{0.14} \\
& =\frac{0.3 \cdot\left[\left(\frac{280.284}{33.634}\right)^{0.02}-1\right]}{0.14} \\
& =0.092 \mathrm{SI} \\
& =\frac{0.14 . t m s}{\left(I_{\text {fault }}\right) a}-1 \\
I_{\text {set }} & \\
& =\frac{0.14 .0 .092}{\left(\frac{280.284}{33.634}\right)^{0.02}-1} \\
& =0.3 \text { detik }
\end{aligned}
$$

2. Perhitungan Setting Ground Fault Relay di sisi GH

$$
\begin{aligned}
\mathrm{I}_{\text {set (p) }} & =11 \% \times \text { Ifault } 1 \text { fasa ketanah } \\
& =0,11 \times 280.284 \\
& =30.83 \mathrm{~A} \\
\mathrm{I}_{\text {set (s) }} & =\mathrm{I}_{\text {set }(\mathrm{p})} / \mathrm{CT} \\
& =30.83 /(600 / 5) \\
& =0.256 \mathrm{~A}
\end{aligned}
$$

Perhitungan Time Multiple Setting dan waktu actual dengan menggunakan persamaan (7),(8)

$$
\begin{aligned}
\text { Tms } & =\frac{t \frac{\left(I_{\text {fault }}\right) a}{I_{\text {set }}}-1}{0.14} \\
& =\frac{0.1 \cdot\left[\left(\frac{280.284}{30.831}\right)^{0.02}-1\right]}{0.14} \\
& =0.032 \mathrm{SI} \\
\mathrm{t} & =\frac{0.14 . t m s}{\left(I_{\text {fault }}\right) a}-1 \\
& =\frac{0.14 .0 .032}{\left(\frac{280.284}{30.831}\right)^{0.02}-1} \\
& =0.1 \text { detik }
\end{aligned}
$$

3. Perhitungan Setting Ground Fault Relay di sisi Kopel

I Gede Agus Yoga Armika : Studi Analisis Kapasitas Pengaman.... 


$$
\begin{aligned}
\mathrm{I}_{\text {set (p) }} & =10 \% \times \text { Ifault } 1 \text { fasa ketanah } \\
& =0,1 \times 280.284 \\
& =28.028 \mathrm{~A} \\
\mathrm{I}_{\text {set (s) }} & =\mathrm{I}_{\text {set (pri) }} / \mathrm{CT} \\
& =28.028 /(400 / 5) \\
& =0.35 \mathrm{~A}
\end{aligned}
$$

Perhitungan Time Multiple Setting dan waktu actual dengan menggunakan persamaan (7),(8)

$$
\begin{aligned}
& \operatorname{Tms}=\frac{t \frac{\left(I_{\text {fault }}\right) a}{I_{\text {set }}}-1}{0.14} \\
&=\frac{0.025 \cdot\left[\left(\frac{280.284}{28.028}\right)^{0.02}-1\right]}{0.14} \\
&=0.008 \mathrm{SI} \\
& \mathrm{t}=\frac{0.14 . t m s}{\left(I_{\text {fault }}\right) a}-1 \\
&=\frac{0.14 .0 .008}{\left(\frac{280.284}{28.028}\right)^{0.02}-1} \\
&=0.025 \text { detik } \\
& \text { TABEL } 7
\end{aligned}
$$

Data Hasil Perhitungan SetTING OCR DAN GFR PENYULANG NGURAH RAI I DAN II

\begin{tabular}{|c|c|c|c|c|c|c|}
\hline \multirow{2}{*}{ Keterangan } & \multicolumn{3}{|c|}{ Setting OCR } & \multicolumn{3}{c|}{ Setting GFR } \\
\cline { 2 - 7 } & GI & GH & Kopel & GI & GH & Kopel \\
\hline I $_{\text {set }}$ & 360 & 330 & 180 & 33.63 & 30.83 & 28.02 \\
\hline Tms & 0.154 & 0.052 & 0.015 & 0.092 & 0.032 & 0.008 \\
\hline Curva & SI & SI & SI & SI & SI & SI \\
\hline $\begin{array}{c}\text { T Actual } \\
\text { (detik) }\end{array}$ & 0.3 & 0.1 & 0.025 & 0.3 & 0.1 & 0.025 \\
\hline
\end{tabular}

C. Simulasi dengan menggunakan Program Etap

Berikut ini simulasi yang akan dilakukan dengan menggambar Single Line diagram dengan menggunakan Program Etap, dan menginput data hasil perhitungan setting OCR dan GFR.

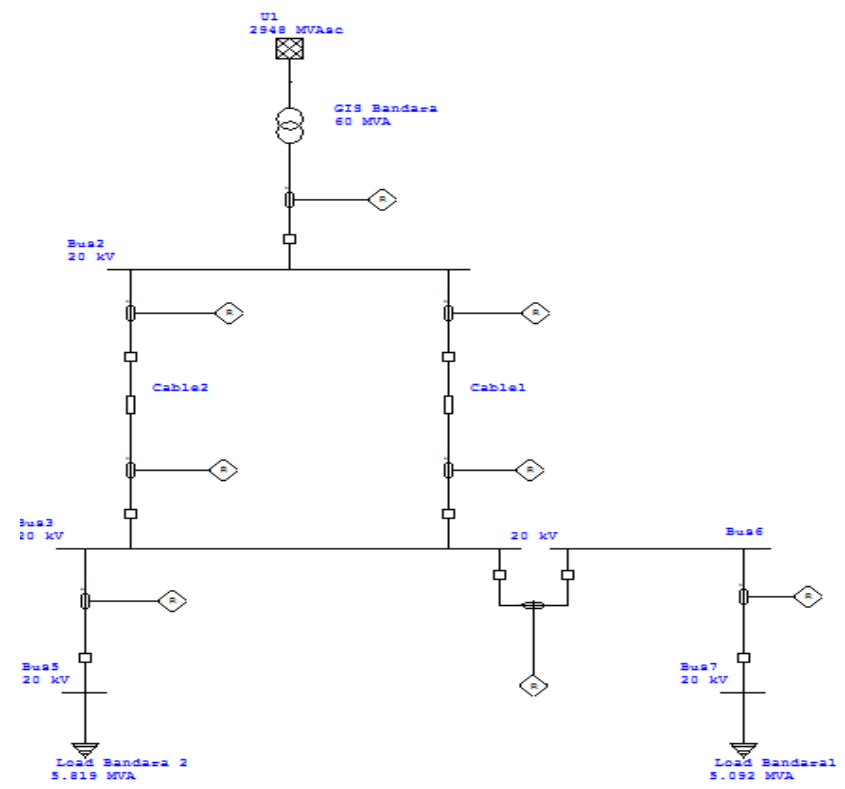

Gambar 4 : Single Line Diagram GH Metering dengan Program Etap

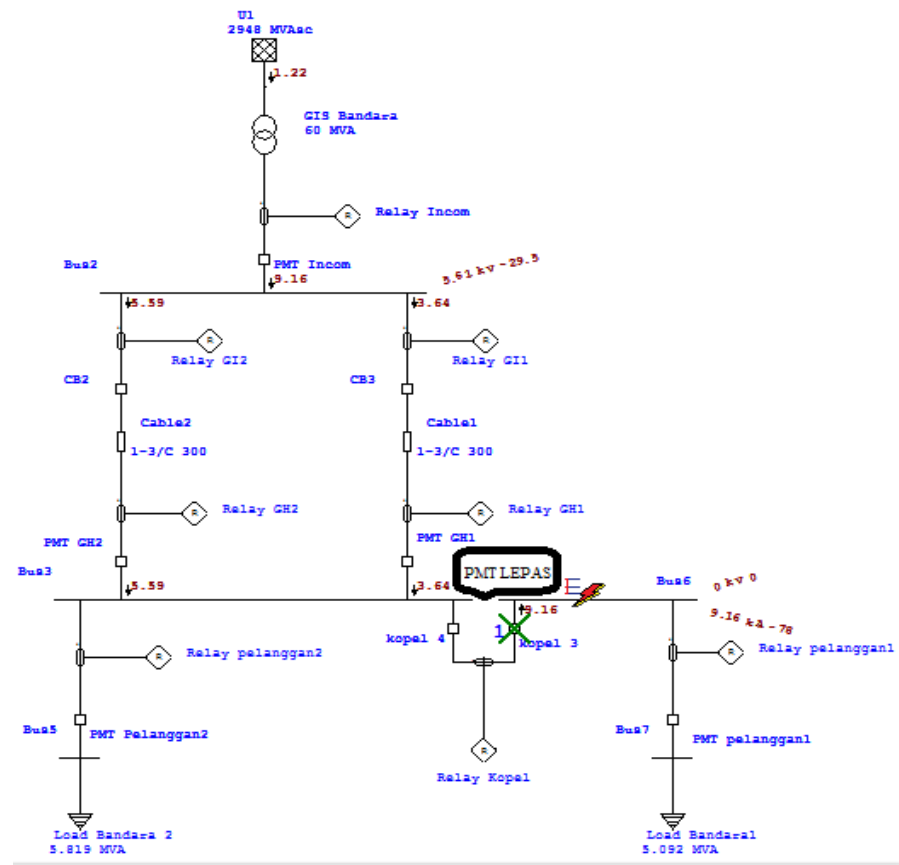

Gambar 5 : PMT bekerja saat diberi gangguan

Bus beban Bandara Ngurah Rai I diberi gangguan dengan menggunakan Star-Protective Device Coordination pada Program ETAP. Pada gambar 5 terlihat saat diberi gangguan pada bus beban Bandara 1, PMT pada kopel 3 terlepas sehingga tidak mengganggu kontinuitas daya listrik di beban bandara II. Rele pengaman pada kopel 3 dapat dikatakan selektif karena memenuhi syarat bekerja pada daerah yang terganggu saja, sehingga sistem yang tidak terganggu dapat beroperasi dengan normal.

\section{SIMPULAN DAN SARAN}

Dari hasil perhitungan arus hubung singkat diperoleh nilai setting arus lebih di kopel 3 sebesar 180 A, setting arus primer ditentukan dari rata-rata penggunaan beban. setting arus sekunder didapat sebesar 2,25 A dengan menggunakan rasio transformator 400/5. Setting arus lebih GFR didapatkan 28.028 A untuk arus primer dan arus sekunder 0.35 A. Pada perhitungan setting arus OCR di sisi kopel 3 didapat nilai Tms sebesar 0.015 SI dengan waktu aktual 0.025 detik, dan nilai Tms setting arus GFR didapat 0.008 SI. Saat terjadi gangguan pada bus beban Bandara I, rele akan bekerja dengan waktu 0.025 detik untuk memerintahkan PMT pada kopel 3 lepas, sehingga tidak mengganggu jaringan di sisi Penyulang Ngurah Rai I dan Penyulang Ngurah Rai II sehingga kontinuitas daya beban Bandara II tetap terjaga. Saran yang dapat dimunculkan dalam penulisan penelitian ini ialah agar dilakukan analisis lebih lanjut pada kopel 3 yang menghubungkan bus beban Bandara I dan bus beban Bandara II dengan menggunakan program atau metode lain untuk mendapatkan hasil yang lebih sempurna. Hasil perhitungan dapat digunakan sebagai acuan untuk menentukan setting arus lebih pada sisi kopel agar di dapat sistem distribusi jaringan yang lebih handal. 


\section{REFERENSI}

[1] Eko Putra (2015). .Analisa Koordinat Setting Rele Pengaman Akibat Uprating di Gardu Induk Gianyar," Teknik Elektro, Universitas Udayana

[2] I. M. Dian Purnawan ."Studi Pengaman Busbar Pada Gardu Induk Amplapura,"Majalah Ilmiah Teknologi Elektro, Vol. 15 No. 1, Januari - juni, 2016

[3] PT PLN (PERSERO) AJ Bali Selatan. 2013 "Data Harian Beban Puncak Pebruari 2016",

[4] Daman, Suswanto. 2009. "Sistem Distribusi Tenaga Listrik”. Padang: Universitas Negeri padang

[5] PT PLN 1995. "Pengantar Rele Proteksi". Semarang : PT. PLN Pusdiklat.

[6] Ramadon, Moh., dkk. 2000. "Perhitungan Arus Hubung Singkat, koordinasi Setting Waktu Relay OCR dan GFR Pada Konfigurasi Jaringan Ring 3 Bus dan Zona Pengaman”. Semarang: PT Polysindo Eka Perkasa.

[7] Indra Baskara."Studi Koordinat Peralatan Proteksi OCR dan GFR pada Penyulang Tibubeneng," Majalah Ilmiah Teknologi Elektro, Vol. 14 No. 2, Juli - Desember, 2015.

[8] PT PLN (PERSERO) APD Bali. 2013 "Single Line GH. Metering”

[9] PT PLN (PERSERO) AJ Bali Selatan. 2013 "Data Panjang Penyulang di GH Metering”

[10] PT PLN (PERSERO) AJ Bali Selatan. 2013 "Data Exsisting setting rele penyulang ngurah rai I dan II"

[11] Anonim (2013) http://distribusitenaga.blogspot.com/2013/11/sistemdistribusi-tenaga-listrik.html

I Gede Agus Yoga Armika : Studi Analisis Kapasitas Pengaman.... 